\title{
Peculiaridades nos Mecanismos Moleculares de Proteínas EM SOLUÇÃO AQUOSA: EXEMPLO DA IMPORTÂNCIA DO EQUILÍBRIO ÁCIDO-BASE PARA APLICAÇÕES EM BIOTECNOLOGIA
}

\author{
Fernando Luís Barroso da Silva \\ Departamento de Química Teórica \\ Centro de Química - Universidade de Lund (Suécia) \\ e \\ Departamento de Física e Química \\ Faculdade de Ciências Farmacêuticas de Ribeirão Preto - São Paulo (Brasil) \\ flbarroso@gmail.com
}

\begin{abstract}
A complexação entre biomoléculas é um tópico importante em vários campos, desde a Bioquímica, às indústrias farmacêutica, alimentar e de cosméticos. A capacidade de descrever e controlar os mecanismos responsáveis por esses processos, em termos de uma descrição molecular, é um desafio para muitas aplicações práticas. Através da modelação molecular e simulações Monte Carlo, descrevemos aqui um mecanismo peculiar: a regulação de cargas em função do equilíbrio ácido-base. Tal fenómeno é responsável por forças mesoscópicas atractivas em sistemas (bio)coloidais, capazes de explicar a complexação de macropartículas com carga do mesmo sinal. Tal é aqui demonstrado através dos complexos lactoferrina-pectina e pectinametilesterase de cenoura-pectina, os quais ilustram este mecanismo geral que pode ser observado em vários outros sistemas coloidais.
\end{abstract}

\section{INTRODUÇÃO}

O comportamento de proteínas e de misturas de biopolímeros em solução é de considerável importância, tanto nas Ciências da Vida (praticamente todas as funções biológicas dependem da interacção entre proteínas), como em tecnologia (por exemplo em formulações farmacêuticas, em tecnologia dos alimentos, na imobilização de enzimas, na separação de proteínas e na tecnologia de (bio)processos em geral) [1-5]. Ao mesmo tempo, este tema oferece uma riqueza de informações e de desafios para o desenvolvimento das ciências exactas, revelando, por exemplo, peculiaridades das interacções físicas fundamentais [6-8].

Um caso particular de equilíbrio químico é o que envolve a protonação de grupos ionizáveis, o que leva ao aparecimento (e variação) da carga eléctrica de macromoléculas em solução aquosa. Como apresentaremos neste trabalho, a flutuação das cargas dos aminoácidos (aa) em função do equilíbrio ácido-base dos grupos ionizáveis resulta num mecanismo molecular bastante sui generis capaz de explicar a atracção de proteínas com cargas eléctricas do mesmo sinal, contrariando o senso comum. Discutiremos aqui as interaç̧ões fundamentais envolvendo complexos de proteínas nestas situações, as quais, recentemente, começaram a ser teoreticamente desvendadas [6-8]. Tomaremos para estudo sistemas que incluem vastas classes de misturas relevantes: os complexos proteína-polissacarídeo. Estes encontram aplicações numa grande diversidade de problemas que extrapolam o contexto biológico, tais como as aplicações em nanoescala, por exemplo, na engenharia de veículos de transporte através do encapsulamento de ingredientes activos (farmacêuticos, alimentares, etc.), na protecção de proteínas adsorvidas, como estabilizantes na tecnologia de alimentos (gelados, bebidas lácteas de frutas, etc.), em (bio)separações, e muitos outros campos (incluindo as condições ideais para a cristalização de proteínas) [1-9].
Controlar sistemas e processos como estes, de maneira completa, requer a quantificação das interacções físicas fundamentais e o entendimento dos parâmetros físico-químicos envolvidos. A força física mais importante, a nível molecular, responsável pela complexação, é de origem electrostática, como indicada pela forte dependência da força iónica e do pH. Apesar da quantidade considerável de trabalhos experimentais, tanto aplicados, como em sistemas modelo, ainda existe relativamente pouco trabalho teórico e de modelação, principalmente que utilizem modelos que apresentem custos computacionais acessíveis e que, ao mesmo tempo, sejam suficientemente detalhados para poderem contribuir para o entendimento físico-químico e para o planeamento de sistemas de uso prático e tecnológico. Assim, tem-se aqui uma oportunidade de combinar ciência básica e aplicada, valendo-se de conceitos típicos dos livros básicos de Química.

Exploraremos aqui sistemas envolvendo a lactoferrina (LF) bovina [10] e a pectinametilesterase de cenoura (PME) [11]. As proteínas do leite (caseínas, albuminas, LF, $\beta$-lactoglobulina, etc.) [10] são sistemas que apresentam uma riqueza de propriedades físico-químicas (muitas destas proteínas são óptimos "protótipos” de biomoléculas envolvidas no metabolismo, em mecanismos de activação de enzimas, como modelos para o enovelamento proteico e para outros estudos bioquímicos), em conjunto com uma importância prática e directa (por exemplo, na estabilização de iogurtes de frutas e do seu alto valor biológico (as proteínas do leite possuem peptídeos bioactivos que actuam como agentes anti-hipertensivos, anti-inflamatórios, anti-cancerígenos, antimicrobianos, reguladores da resposta imune, entre outros), para a qual há um grande volume de dados experimentais a necessitarem de uma melhor interpretação sob o ponto de vista físico. Já a PME é uma enzima que catalisa a pectina e apresenta características interessantes para uma comparação com a LF. 


\section{INTERACCÕES ELECTROSTÁTICAS EM SOLUÇ̃̃O AQUOSA}

De acordo com a classificação tradicional das forças da natureza (gravitacionais, electromagnéticas, nucleares fortes e nucleares fracas), as forças intermoleculares são descritas como interacções de origem electromagnética. A energia de interacção entre dois átomos resulta das forças eléctricas entre as entidades carregadas de que estes átomos são feitos. Por simplicidade, e balizando a nossa discussão de forma clássica, assumiremos que a origem da carga eléctrica destes átomos provém dos electrões e dos protões. Consequentemente, são possíveis diferentes forças eléctricas: interacção entre multipólos permanentes, indução, dispersão, repulsão electrostática e transferência de carga [12].

Quando se aborda o tema “interacções electrostáticas em e entre biomoléculas”, na literatura a linguagem não é sempre precisa. Normalmente, tem-se em mente apenas as interacções entre cargas fixas (interacções de Coulomb), mesmo que todas as interacções assinaladas acima sejam por natureza electrostáticas e estejam presentes nas biomoléculas. É importante então esclarecer que, no caso em estudo, se consideram interacções de Coulomb, não sendo consideradas as distorções nas nuvens electrónicas e/ou transferência de carga.

A combinação das características dos sistemas (bio)coloidais com o $\mathrm{pH}$, electrólitos e temperatura resulta numa diversidade complexa e rica de mecanismos peculiares associados à lei de Coulomb. Aparecem forças mesoscópicas de importância elevada para a organização e função molecular de sistemas biológicos e de interesse industrial [7-8]. Apesar das aplicações em diferentes áreas (das proteínas ao cimento!), diversidade de formas geométricas dos sistemas e interesses científicos, os principais “actores” desses mecanismos são sempre as cargas e os tamanhos iónicos. Alguns sistemas também podem apresentar efeitos iónicos específicos, conhecidos como “efeito Hofmeister” [13].

Centrando-nos na carga e no tamanho iónico, os fenómenos electrostáticos são usualmente classificados de acordo com o chamado "regime de acoplamento electrostático" [14]: (a) fraco (raf), onde os iões livres (contra-iões e sal adicionado) são partículas monovalentes (ex. $\mathrm{Na}^{+}$), as quais blindam as interacções electrostáticas, e o sistema é caracterizado por forças repulsivas, como descrito pela teoria de DVLO [15]), e (b) forte (raF), onde iões multivalentes (ex. $\mathrm{Ca}^{2+}$ ) dão origem a forças atractivas devido a correlação (de carga e tamanho) ião-ião (correlações iónicas) [16]. Estas correlações também são responsáveis pelo fenómeno conhecido como "sobrecarga" (overcharging) $[17,18]$. O parâmetro de acoplamento electrostático é dado por: $\Xi=2 \pi z_{k}^{3} l_{b}^{2} a$, onde $z_{k}$ é a valência do contra-ião, $l_{b}$ é o comprimento de Bjerrum $\left[l_{b}=e^{2} / 4 \pi \varepsilon_{0} \varepsilon_{s} K T\right]$, onde os termos $e, \varepsilon_{0}, \varepsilon_{s}, K$ e $T$ são, respectivamente, a carga elementar $\left(e=1,602 \times 10^{-19} \mathrm{C}\right)$, a permissividade do vácuo $\left(\varepsilon_{0}\right.$ $\left.=8,854 \times 10^{-12} \mathrm{C}^{2} / \mathrm{Nm}^{2}\right)$, a constante dieléctrica do solvente, a constante de Boltzmann $\left(K=1,3807 \times 10^{-23} \mathrm{~J} \cdot \mathrm{mol}^{-1} \cdot \mathrm{K}^{-1}\right)$ e a temperatura (expressa em kelvin), i.e., uma medida da distância na qual duas cargas elementares, num dado solvente, interagem com uma unidade de energia térmica (KT) [14]. Pode ser observado directamente que o aumento de $z_{k}$ dos contra-iões aumenta $\Xi$. Para $\Xi>>1$, os contra-iões são atraídos fortemente pela superfície carregada e verifica-se uma tendência para o sistema sofrer atracção. No entanto, esta é uma descrição simplificada da realidade. Mesmo no raf, podem ser observados comportamentos anómalos (i.e. atracção) devido a outros fenómenos: (a) blindagem electrostática devido a concentração do macroião [19] e (b) mecanismo de regulação de cargas (reg) [6-8,20]. Neste trabalho, abordamos especificamente os efeitos relacionados com a reg.

As proteínas são entidades ionizáveis cuja carga líquida pode variar de positiva a negativa em função do aumento do pH, definindo a sua estabilidade e função [21-23]. Dependendo da quantidade de grupos tituláveis ( $\alpha$-carboxílico, fenol, imidazol, $\varepsilon$-amino, guanidina, carboxílico aspártico, carboxílico glutâmico, $\alpha$-amino e tiol) [22-23], da sua localização na sequência primária, da configuração tridimensional e do pH, algumas proteínas são altamente carregadas. Outras moléculas biológicas como o DNA e o RNA comportam-se de maneira semelhante [22]. O ambiente biológico também contém iões salinos com valências variadas, os quais podem modular as interacções e, fisiologicamente, regular as macromoléculas [24].

A regulação de cargas é o mecanismo particular gerado pela flutuação da carga dos aa em função do equilíbrio químico num determinado $\mathrm{pH}$, o que resulta em forças atractivas para a complexação macromolecular mesmo no regime

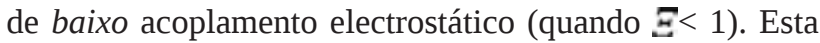
flutuação é medida pela capacitância $(C)$ da proteína, definida como $\left\langle Z^{2}>-<Z\right\rangle^{2}$, onde $Z$ é a valência da proteína numa dada configuração para um determinado $\mathrm{pH}$ [6-8, 25]. Os <> indicam valores médios e reflectem o facto dos aa estarem protonados ou não. Experimentalmente, $C$ pode ser determinada de acordo $\operatorname{com} C \propto \frac{d Z}{d p H}[7]$.

Em termos históricos, as abordagens teóricas para o problema da complexação remetem-nos para o trabalhos pioneiros do holandês J.T.G. Overbeek no que respeita ao desenvolvimento das primeiras teorias para a complexação de biopolímeros carregados com carga oposta (especialmente no contexto de coacervados) [31]. Alguns estudos [2-3] vieram, no entanto, colocar em questão as teorias desta natureza, por terem revelado um aparente paradoxo: a formação de complexos moleculares em condições de $\mathrm{pH}$ onde as cargas "líquidas" das duas macromoléculas envolvidas têm o mesmo sinal, na presença de baixa concentração de contra-iões monovalentes, de modo a que as correlações iónicas não sejam expressivas. O termo complexação "no sentido errado” passou então a ser usado, significando que o polianião forma um complexo com a proteína a um valor de $\mathrm{pH}$ acima do seu ponto isoeléctrico (pI) [3]. A interpretação concentrou-se na explicação baseada na existência de "patamares de carga”, regiões localizadas com alta complementaridade de densidade de carga na superfície proteica [3]. Seguindo este raciocínio, um monómero do polianião deveria ligar-se a uma região com elevada concentração 
de cargas positivas da outra macromolécula, e vice-versa. O mesmo tipo de argumento é usado quando se discute a interacção de duas proteínas no seu ponto isoeléctrico ( $\mathrm{pH}$ $\approx \mathrm{pI}$ ). Uma alternativa mais formal seria em termos de uma expansão multipolar, isto é: para dois macroiões neutros, os termos dominantes seriam as interacções dipolo-dipolo, dipolo-quadripolo, etc. [6-8].

Kirkwood e Shumaker (KS) [32], em 1952, previram analiticamente que as flutuações nas cargas dos aa (decorrentes do equilíbrio ácido-base e no sentido da variação da carga fixa de um monopólio elétrico, e não da flutuação da densidade electrónica de um átomo) de duas proteínas podem resultar em forças electrostáticas atractivas. Para a condição de $\mathrm{pH} \approx \mathrm{pI}$ [6-8], demonstramos para vários complexos que a atracção é possível em termos puramente electrostáticos, podendo ser de várias unidades de energia térmica $(K T)$. Em termos analíticos, a energia livre de interacção $[A(R)]$ para duas macromoléculas $\mathrm{A}$ e $\mathrm{B}$, separadas pela distância $R$ pode ser calculada de acordo com:

$\frac{A(R)}{K T} \approx \frac{l_{B}\left\langle Z_{A}\right\rangle\left\langle Z_{B}\right\rangle}{R}-\frac{l_{B}^{2}}{2 R^{2}}\left(C_{A} C_{B}+C_{A}\left\langle Z_{B}\right\rangle^{2}+C\right.$.

onde o segundo termo corresponde à regulação de cargas, e é sempre atractivo.

\section{Modelos}

Utilizando modelos simplificados, o nosso objectivo, neste trabalho, é ilustrar o mecanismo da regulação de cargas. Pela evidência dos efeitos de sal e de $\mathrm{pH}$, é sabido que as interacções electrostáticas devem ter um papel de destaque. Por isso, essa interacção será a principal componente do modelo. Invocando um número mínimo de parâmetros, têm sido concebidos e resolvidos por simulações Monte Carlo (MC) vários modelos contínuos mais mesoscópicos, conhecidos como coarse graining models [6-8, 25, 26]. Os modelos verdadeiramente atomísticos, incluindo moléculas de água explícitas, ainda não conseguem atingir as escalas de tempo e de tamanho de forma a explorar a complexação de proteínas-proteínas a diferentes valores de $\mathrm{pH}$ e de força iónica, e, menos ainda, de proteínas-polissacarídeos através de simulações computacionais. O custo computacional (tempo de processamento e exigência de supercomputadores, por exemplo) torna-se proibitivo nesta classe de modelo. Por outro lado, os modelos simplificados que ainda são frequentemente usados em polímeros e em ciência coloidal (como os modelos de esferas ligadas para representar um polímero, ou modelos esféricos para representar uma proteína) dificilmente podem ser aplicados a sistemas reais quando a heterogeneidade química é crucial. Esta situação foi resolvida desenvolvendo modelos intermédios, em termos de detalhe, onde podemos acomodar os detalhes mais relevantes da heterogeneidade química das proteínas. Isso inclui, por exemplo, a descrição da forma da proteína ao nível de modelação dos seus aa, com a descrição da localização de cada carga eléctrica ao nível dos grupos químicos individuais [6-8, 25]. Podemos também incluir detalhes da associação/dissociação de $\mathrm{OH}^{-}$e de $\mathrm{H}^{+}$, os quais são cruciais para a complexação $[6-8,20]$ mas que são, normalmente, ignorados, mesmo nas simulações ditas de detalhe atomístico. É importante notar que uma comparação recente entre uma simulação atomística com flexibilidade proteica e água explícita usada para caracterizar interacções efectivas entre moléculas de lisozima mostrou as mesmas características principais que modelos simplificados [27]. Em todas as simulações MC, a temperatura foi mantida constante em $298 \mathrm{~K}$ e as espécies carregadas foram confinadas dentro de um célula esférica electricamente neutra, cujo raio $R_{\text {celula }}$ é determinado pela concentração de proteína $\left(\mathrm{c}_{\mathrm{p}}\right)$. Isto corresponde ao chamado "modelo da célula” [28]. A motivação física deste modelo é equivalente a dividir a solução electrolítica em células, onde cada uma contém uma macromolécula (ou um par de macromoléculas) com os seus electrólitos (contra-iões e o sal adicionado). É assumido que não existem interacções entre as diferentes células do sistema real. A única maneira em que são consideradas as interações entre as células é indirectamente através da definição de $c_{\mathrm{p}}$.

As cargas iónicas livres são descritas pelo modelo primitivo restrito. Cada ião móvel $k$ com valência $z_{k}$ é tratado explicitamente como uma esfera-rígida de raio $R_{k}$, enquanto o solvente é tratado por um meio dieléctrico sem estrutura caracterizado pela sua constante dieléctrica estática $\varepsilon_{\mathrm{s}}$. Suportado por estudos anteriores [6,19], não é introduzida no modelo qualquer descontinuidade dieléctrica. A mesma constante dieléctrica $\varepsilon_{\mathrm{s}}$ é assumida para modelar o solvente e o interior de todas as espécies. A macromolécula é tratada como um corpo rígido fixo no centro da célula de simulação. A justificação para se adoptar um modelo sem graus internos de liberdade está no facto de estarmos interessados em caracterizar propriedades termodinâmicas como as derivadas da energia livre, as quais são função da distância de separação entre as espécies (p. ex. o potencial de força média).

Os sistemas a simular consistem tipicamente numa proteína, ou numa proteína e uma cadeia de polissacarídeo, imersa numa solução electrolítica, estando todo o sistema confinado nesta “caixa de simulação” esférica e neutra como se ilustra na Figura 1. As coordenadas dos átomos proteicos foram obtidas da base de dados de proteínas (http://www.pdb.org), cujos códigos para referências são 1BLF (LF) e 1GQ8 (PME).

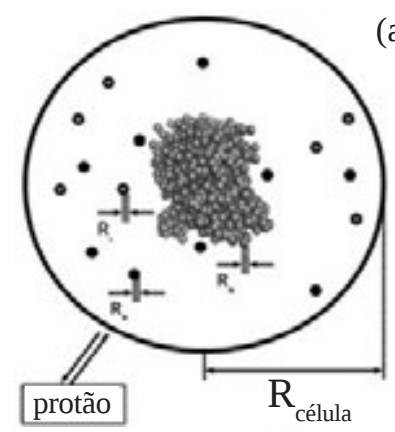

(a)

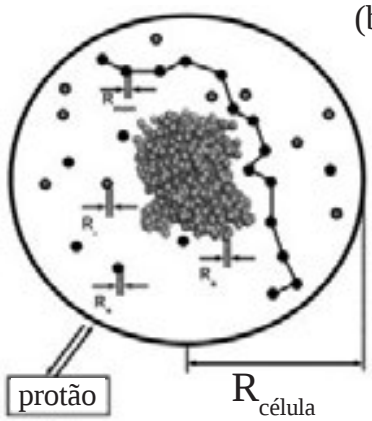

(b)

Figura 1 - Representação esquemática do modelo da célula, onde uma macromolécula biológica é modelada considerando todos os seus átomos e a solução electrolítica (contra-iões e sal adicionado) é descrita pela modelo primitivo restrito. (a) Na ausência do polielectrólito; (b) Na presença do polielectrólito 
A Hamiltoniana efectiva consiste essencialmente num termo de curto alcance do tipo esfera-rígida, e num termo de longo alcance. É também incluído um termo restritivo para manter todas as partículas confinadas no interior da célula. Esta estratégia permite o tratamento exacto das interacções electrostáticas, inclui integralmente o efeito de força iónica, reduz o custo computacional para obtenção da energia livre, e evita ainda os inconvenientes de escolha dos campos de força, "truncagem" das interacções de longo alcance e incompatibilidade das escalas de tempo entre os valores reais do evento biológico e o passível de ser simulado.

Desta forma, dois sítios $i$ e $j$ (tanto uma carga de um aa da proteína, um ião livre, ou ainda um monómero do polielectrólito) separados espacialmente por uma distância $r_{i j}$ $>R_{i}+R_{i}$ contribuem com a energia potencial electrostática $\left[U^{i e l e}\left(r_{i j}\right)\right]$ simplesmente pelo potencial de Coulomb clássico:

$U^{\text {ele }}\left(r_{i j}\right)=\frac{Z_{i} Z_{j} e^{2}}{4 \pi \varepsilon_{0} \varepsilon_{s} r_{i t}}$

onde $z_{i}$ e $z j$ denotam a valência das cargas $i$ e $j$, respectivamente. Quando $r_{i j} \leq R_{i}+R_{i j}$, é necessária a prevenção do colapso Coulombico entre as cargas e a modelação da repulsão característica entre as nuvens electrónicas dos átomos. Isto é feito através da introdução do potencial de esfera-rígida $\left[U^{e r}\left(r_{i j}\right)\right]$ :

$U^{e r}\left(r_{i j}\right)=\left\{\begin{array}{l}\infty, \text { para } r_{i j} \leq\left(R_{i}+R_{j}\right) \\ 0, \text { nas demais situaç̧es }\end{array}\right.$

Este potencial de interacção também modela a exclusão do volume dos macroiões. Para manter todas as espécies confinadas dentro da célula, é incluído um campo externo $\left[U^{e x t}\left(r_{j}\right)\right]$ :

$U^{\text {ext }}\left(r_{i}\right)=\left\{\begin{array}{c}0, \text { para }\left(R_{i}+R_{p}\right) \leq n \leq R_{\text {ceture }} \\ \infty, \text { nas demais situaçōes. }\end{array}\right.$

A energia configuracional total do sistema $\left[U\left(\left\{\boldsymbol{r}_{k}\right\}\right)\right]$ é definida pela combinação das Eqs. (2)-(4):

$U\left(\left[r_{k}\right\}\right)=\sum_{i=1}^{N_{e}+N_{s}} U^{\text {ext }}\left(r_{i}\right)+\frac{1}{2} \sum_{i=1}^{N} \sum_{j=1}^{N}\left[U^{\text {ele }}\left(r_{i j}\right)+U^{\text {er }}\left(r_{i j}\right)\right.$ (Eq. 5)

onde $N_{c}$ e $N_{s}$ correspondem aos números do contra-iões e iões de sal adicionados ao sistema, respectivamente. $\mathrm{O}$ número total de cargas é dado por $N=N_{c}+N_{s}+N_{P}$, o que inclui também o número de átomos carregados da proteína $\left(N_{P}\right)$. Nas simulações envolvendo o polielectrólito, é adicionado, na Eq. 5, o termo de potencial de interacção de ligação $\left(u^{\text {ligasão }}\right)$. Assumimos uma cadeia altamente flexível, formada por $N_{\text {mon }}$ esferas rígidas de raio $R_{\text {mon }}$ com carga eléctrica $\left(Z_{\text {mon }} e\right)$ e ligadas pelo potencial harmónico de interacção. $\mathrm{O} u^{\text {ligacão }}$ entre dois monómeros vizinhos é calculado como:

$\beta u^{\text {ligaçato }}=\frac{l_{b}}{2 r_{\min }^{3}} \sum_{i=1}^{N_{\operatorname{mon}}-1}\left(r_{i, i+1}\right)^{=}$

onde $r_{i^{\prime}{ }_{i+1}}$ é a distância entre o monómero $i$ e o monómero $i+1, r_{\min }$ é a distância de separação correspondente ao mínimo de energia para um dímero. Em todas as simulações com polielectrólitos, adoptamos $N_{\text {mon }}=21$ monómeros, $R_{\text {mon }}=2$
$\AA, Z_{\text {mon }}=-1$ e $r_{\min }=4 \AA$ (isso corresponde a uma separação monómero-monómero de aproximadamente $7.4 \AA$ ). A carga dos monómeros do polielectrólito é mantida constante.

Um reservatório de protão é acoplado à célula para estabelecer um $\mathrm{pH}$ constante no sistema. Após algumas tentativas de mover as cargas móveis, é feita uma tentativa de remover/inserir protões nos grupos tituláveis da proteína. Na verdade, a protonação de um grupo ácido significa que um ácido foi adicionado à solução. Então, na simulação, a protonação é balanceada pela inserção de uma carga negativa móvel para manter a electroneutralidade do sistema. A aceitação/rejeição de uma tentativa para mudar o estado de ionização de um resíduo é baseada na variação de energia:

$\Delta U_{\text {minsto }}=\Delta U_{\text {ets }} \pm k T \ln 10\left(p H-p K_{Q-}=\right.$

onde $\Delta U_{e l e}$ é a correspondente variação na energia Coulombica, e $p K_{0}$ é a constante de dissociação do composto modelo. Esses valores são retirados de resultados experimentais da literatura [22].

Diversas quantidades características (e que podem ser directamente comparadas com dados experimentais) podem ser medidas em simulações como as aqui reportadas (p.ex. propriedades termodinâmicas e microscópicas tais como energia livre de complexação, segundo coeficiente do virial, estequiometria da ligação, constante de ligação, etc.). Aqui, apresentaremos curvas de titulação ( $\mathrm{Z}$ vs. $p H)$, curvas de capacitância ( $C$ vs. $p H)$ e potenciais de força média [w(r)].

As curvas de titulação e de capacitância foram determinadas a partir da valência da proteína em função do $\mathrm{pH}$ ao longo da fase de produção das simulações MC. O w(r) foi determinado através do uso de histogramas, i.e. de funções de distribuição radial $[g(r)]$ determinadas através de histogramas de largura $0,5 \AA$, e depois convertidas em $w(r)$ $[=-K T \ln g(r)]$.

\section{TITULAÇÃO DAS PROTEÍNAS}

A primeira etapa no estudo de qualquer processo envolvendo interacções electrostáticas é sempre a caracterização das proteínas individuais (sem a presença da segunda macromolécula) em solução electrolítica. Além da importância per si, isso permite a escolha das janelas de $\mathrm{pH}$ mais prováveis para a complexação. Durante as simulações em diferentes valores de $\mathrm{pH}$, são medidas propriedades como as valências (ou cargas) médias e suas flutuações, e, desta maneira, quantificada a grandeza que se convencionou [68, 25] chamar de capacitância da proteína. As Figuras 2 e 3 mostram estas curvas para as proteínas LF e PME, obtidas após $10^{7}$ ciclos de MC na fase de produção. Esses dados descrevem o comportamento resultante de cada um dos grupos tituláveis na presença de todos os demais que estão presentes na estrutura enovelada para cada um desses polipeptídeos, reflectindo ainda os efeitos das cargas eléctricas livres (contra-iões e sal) da solução electrolítica.

Através das curvas de titulação, pode determinar-se os valores de $\mathrm{pH}$ em que estas proteínas estão carregadas posi- 
(a)

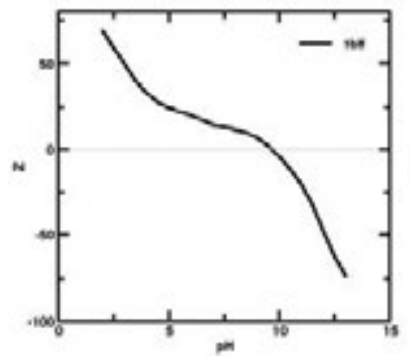

(b)

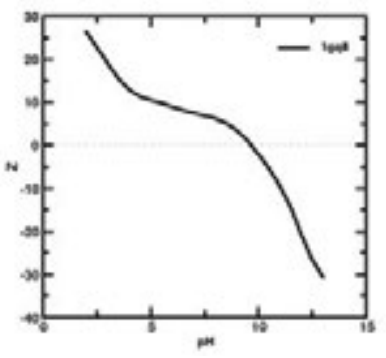

Figura 2 - Curvas de titulação obtidas em simulações Monte Carlo, em baixa concentração salina e proteica, para as proteínas (a) LF e (b) PME. A concentração de sal é $0,025 \mathrm{M}$ numa caixa esférica de raio $R_{\text {célula }}=200 \AA$

(a)

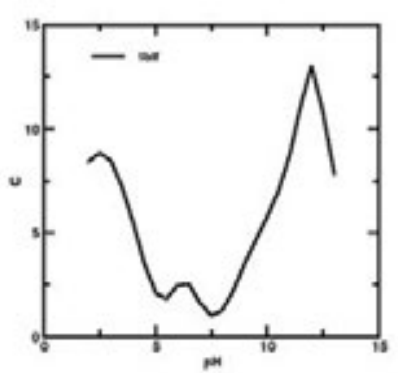

(b)

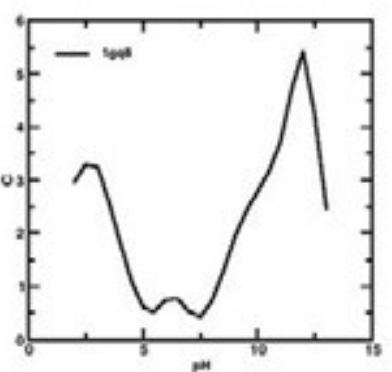

Figura 3 - Curvas de capacitância obtidas em simulações Monte Carlo, em baixa concentração salina e proteica, para as proteínas (a) LF e (b) PME. Restantes condições como descrito na Figura 2

tiva e negativamente, assim como os seus pIs. Para a LF e PME, os valores de pI são 9,7 e 9,6, respectivamente. Na literatura, são reportados valores experimentais de 6,8-9,0 para a LF [29] e >9,3, para a PME [11]. Estas diferenças são esperadas em função das dificuldades em precisar as quantidades reais de iões presentes em experiências laboratoriais (os quais contribuem com a blindagem electrostática), as características e precisão das técnicas experimentais, etc. Isso pode ser notado pelo grande intervalo de valores reportados experimentalmente. Outro aspecto a ser considerado é o facto de utilizarmos nas simulações estruturas cristalográficas, as quais estão sujeitas a artefactos, e ainda serem mantidas rígidas. É interessante notar que outros trabalhos teóricos fornecem o valor de 9,4 para o pI da LF [30]. Embora os pIs destas proteínas apresentem valores semelhantes, a carga da LF é sempre mais positiva e negativa, respectivamente, nos regimes de pH ácido e básico, o que acentua as interacções nesses extremos de $\mathrm{pH}$.

As flutuações de carga são maiores quando o pH está próximo do pI de um determinado aminoácido. Por exemplo, uma proteína rica em lisosima tende a ter um pico no $\mathrm{pH}$ 10,4 ( $\mathrm{p} K_{\mathrm{alis}}=10,4$ [22]). Destas proteínas, a LF é a molécula com mais lisinas (53), em comparação com a PME, que possui 15. No pH 10,4, as suas capacitâncias são, respectivamente, 6,7 e 3,1. A proporção não é exactamente a mesma do número de resíduos, pois, outros aa presentes na estrutura afectam a ionização destas lisinas, assim com a estrutura tridimensional particular de cada proteína. Por estas curvas de capacitância se percebe a semelhança qualitativa entre a LF e a PME, o que se tornará particularmente interessante nas discussões abaixo sobre a reg, visto ser este um parâmetro importante para o mecanismo. Por esta análise, já é possível prever que a LF tende a formar complexos mais estáveis do que a PME. Note-se como os picos são bem mais elevados nos pHs mais básicos da LF e PME, em comparação com os valores calculados no pI.

\section{CompleXação}

Estudamos aqui o efeito do $\mathrm{pH}$, analisando os complexos LF-pectina e PME-pectina. Para garantir que os efeitos de correlação ião-ião acima discutidos possam ser desconsiderados, as simulações foram executadas apenas com iões monovalentes (1:1). Foram considerados detalhes atómicos das proteínas no nosso modelo. Todos os átomos presentes nas estruturas tridimensionais são descritos por esferas rígidas de raio $R_{a}=2 \AA$ e valência $Z_{a}$, os quais não podem mover-se durante as simulações. A proteína é colocada no centro da caixa de simulação. As cargas são atribuídas e variadas em função do $\mathrm{pH}$. O protocolo para a titulação é o discutido acima (Secção 3) e o polielectrólito é introduzido como espécie real na célula de simulação junto com a proteína e demais iões - como se ilustra na Figura $1 \mathrm{~B}$. O polímero pode movimentar-se livremente por toda a célula respeitando o critério de Metropolis.

Estas simulações foram realizadas no ensemble semi-canónico usando o algoritmo padrão de Metropolis MC [26], com os deslocamentos aleatórios das espécies móveis (contra-iões, iões do sal e monómeros do polianião) dentro da célula de $R_{\text {célula }}=220 \AA$ Å. Foram necessários $10^{9}$, $10^{10}$ e $10^{11}$ ciclos de MC para as fases de pré-equilíbrio, equilíbrio e produção, respectivamente.

Na Figura 4 apresentamos os resultados de $w(r)$ a diferentes valores de $\mathrm{pH}$ (os quais foram escolhidos na vizinhança do pI de cada proteína, capturando regimes de atracção e de repulsão). Para ambos os sistemas observamos que a atracção ocorre em condições onde as cargas das moléculas têm o mesmo sinal. Esta atracção observada é fortemente dependente do $\mathrm{pH}$ e é resultado de uma propriedade físico-química intrínseca das proteínas: a sua habilidade em regular a sua carga [6-8, 20]. Isso pode ser comprovado através da observação de que quanto maior a capacitância da proteína $(C)$, maior o poço de potencial encontrado. Tal facto está de acordo com o previsto pela Eq. 1, onde, mantendo-se todos os termos constantes, um aumento no valor de $C$ provoca um crescimento significativo na componente atractiva da energia livre. Para a PME, por exemplo, no intervalo de $\mathrm{pH}$ entre 8 e 10, a $C$ desta proteína aumenta de 0,7 a 2,8. De forma consistente, os dados das simulações MC, mostrados na Figura 4B, indicam que o sistema deixa de ser repulsivo (em $\mathrm{pH} 8$ com $C=0,7$ ) e torna-se atractivo (em pH 10 com $C=2,8$ ). Das duas proteínas aqui estudadas, a LF é a molécula que possui as capacitâncias mais elevadas e, por consequência, exibe mínimos bastante pronunciáveis em $w(r)$. Nas três curvas de $w(r)$ mostradas na Figura 4A, as atracções observadas na derivada da energia livre têm mínimos superiores a -15KT. Esse é um sistema que apresenta elevada tendência de complexação. 


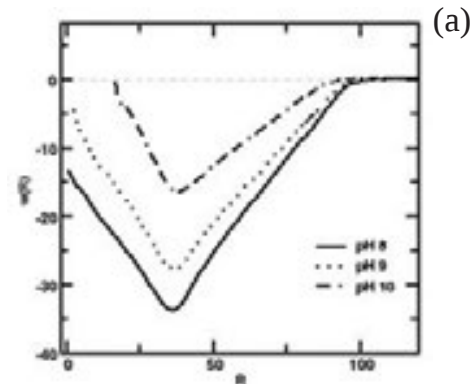

(a)

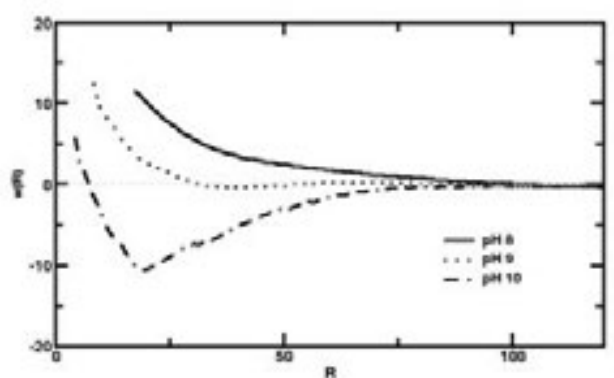

(b)

Figura 4 - Potencial de força média $[w(r)]$ em função da distância de separação do centro da proteína e do centro de massa do polianião (carga -21e) a diferentes valores de $\mathrm{pH}$. A concentração de sal é baixa $(7,5 \mathrm{mM})$ e a de proteína é de $0,4 \mathrm{mM}$. Dados obtidos em simulações Monte Carlo. (a) pectina-LF (PDB id 1BLF). (b) pectina-PME (PDB id 1GQ8)

\section{Conclusão}

Através de simulações Monte Carlo, demonstramos um mecanismo molecular peculiar, importante e geral observado no domínio (bio)coloidal. A regulação de cargas resulta em forças mesoscópicas atractivas de origem puramente electrostática, as quais revelam as limitações da teoria de DVLO, um dos landmarks da ciência dos colóides. Tal mecanismo evidencia a riqueza e a complexidade da combinação das características dos sistemas (bio)coloidais com o pH, electrólitos e temperatura, os quais abrem novos horizontes para o entendimento e a manipulação racional da organização e da função molecular de sistemas biológicos e dos sistemas de interesse industrial.

\section{Agradecimentos}

Agradecemos o apoio de Capes/MCT, Fapesp e Swedish Research Council.

\section{REFERÊNCIAS}

[1] T.M. Devlin, Textbook of Biochemistry with Clinical Correlations, Wiley-Liss, Nova Iorque, 1997

[2] S.L. Turgeon, C. Schmitt, C. Sanchez, Curr. Opin. Colloid. Interf. Sci. 12 (2007) 166-178

[3] R. de Vries, M. Cohen-Stuart, Curr. Opin. Colloid. Interf. Sci. 11 (2006) 295-301

[4] O.G. Jones, D.J. McClements, Adv. in Colloid and Interface Science 167 (2011) 49-62

[5] K. Chen, Biomacromolecules 12 (2011) 2552-2561

[6] F.L.B. Da Silva, B. Jönsson, M. Lund, T. Åkesson, J. Phys. Chem. B 110 (2006) 4459-4464

[7] B. Jönsson, M. Lund, F.L.B. Da Silva, in "Food Colloids: Self-Assembly and Material Science”; E. Dickinson, M.E. Leser (eds), Royal Society of Chemistry, 2007, Cap. 9, p. 129-154

[8] F.L.B. Da Silva, B. Jönsson, Soft Matter 5 (2009) 28622868

[9] R. Piazza, J. Crystal Growth 196 (1999) 415-423

[10] H.M. Farrell Jr., R. Jimenez-Flores, G.T. Bleck, E.M. Brown, J.E. Butler, L.K. Creamer, C.L. Hicks, C.M. Hollar, K.F. Ng-Kwai-Hang, H.E. Swaisgood, J. Dairy Sci. 87 (2004) 1641-1674

[11] R.P. Jolie, T. Duvetter, A.M. van Loey, M.E. Hendrickx, Carbohydrate Research 345 (2010) 2583-2595
[12] G.C. Maitland, M. Rigby, E.B. Smith, W.A. Wakeham, "Intermolecular forces - Their origin and determination. Oxford University Press”, Oxford, 1981

[13] A. Salis, F. Cugia, D.F. Parsons, B.W. Ninham, M. Monduzzi, Phys. Chem. Chem. Phys. 14 (2012) 4343-434

[14] A. Naji, A. Arnold, C. Holm, R. Netz, Europhysics Letters 67 (2004) 130-136

[15] E.J.W. Verwey, J.Th.G. Overbeek, "Theory of the Stability of Lyophobic Colloids”, Elsevier, Amsterdam, 1948

[16] M. Borkovec, B. Jönsson, G.J.M. Koper, “Ionization Processes and Proton Binding in Polyprotic Systems: Small Molecules, Proteins, Interfaces and Polyelectrolytes”, Leiden University, 1999

[17] J. Lyklema, Colloids and Surfaces A: Phys. Eng. Aspects 291 (2006) 3-12

[18] C. Labbez, B. Jönsson, M. Skarba, M. Borkovec, Langmuir 25 (2009) 7209-7213

[19] S.J. Carvalho, R.C.T. Ghiotto, F.L.B. Da Silva, J. Phys. Chem. B 110 (2006) 8832-8839

[20] P.M. Biesheuvel, A. Wittemann, J. Phys. Chem. B 109 (2005) 4209-4214

[21] J.B. Matthew et al., CRC Crit. Rev. Biochem. 18 (1985) 91197

[22] T.K. Harris, G.J. Turner, IUBMB Life 53 (2009) 85-98

[23] Y. Nozaki, C. Tanford, Methods Enzymol. 11 (1967) 715734

[24] B. Garcia-Moreno, Methods Enzymol. 259 (1995) 512-538

[25] A.A.R. Teixeira, M. Lund, F.L.B. Da Silva, J. Chem. Theo. Comput. 6 (2010) 3259-3266

[26] D. Frenkel, B. Smit, "Understanding Molecular Simulation: From Algorithms to Applications (Computational Science)", Academic Press, 2001

[27] G. Pellicane, G. Smith, L. Sarkisov, Phys. Rev. Letts. 101 (2008) 248102-4

[28] R.A. Marcus, J. Chem. Phys. 23 (1955) 1057-1068

[29] F. Berlutti, F. Pantanella, T. Natalizi, A. Frioni, R. Paesano, A. Polimeni, P. Valenti, Molecules 16 (2011) 6992-7018

[30] J.M. Steijns, A.C.M. van Hooijdonk, Br. J. Nutr. 84, Suppl. 1 (2000) S11-S17

[31] J.T.G. Overbeek, M.J. Voorn, J. Cell. Comp. Physiol. 49, Suppl. 1 (1957) 7-26

[32] J.G. Kirkwood, J.B. Shumaker, Proc. Natl. Acad. Sci. USA 38 (1952) 863-871 